\title{
THE FEATURES OF THE SPECIFICATION OF THE LAW AND LEGAL QUALIFICATION IN THE PROCESS OF CONSTITUTIONAL JUDICIAL CONTROL
}

\author{
Yuliya A. Gavrilova \\ Volgograd State University, Volgograd, Russian Federation
}

\begin{abstract}
Introduction: the article deals with the problem of the interaction of specifying the law and legal qualifications in the process of the activities of the Constitutional Court of the Russian Federation. This problem has not been studied deeply in Russian law. Meanwhile, it is of significant theoretical and practical importance for the development of legislation and forecasting the main trends in legal practice. The purpose of the study is to determine the peculiarities of the concepts "specification of law" and "legal qualification" in constitutional judicial proceedings. The objectives of the study are to highlight the main features and the role of law specification, to characterize the nature and provide examples of legal qualification in the procedure of abstract judicial control. Methods: the article uses formal legal, concrete sociological and comparative legal research methods. Results: the specification of law has a multifunctional target character in the process of constitutional judicial proceedings and can be meaningpreserving, meaning-changing and meaning-creating according to the criterion of orientation towards the knowledge of the meaning of law. This shows its universal nature for the legal system, which distinguishes it from its specification in lawmaking and law enforcement. An essential feature of the constitutional- judicial specification of the law is also an orientation towards the constitutionalization of law enforcement practice. The legal qualification has a multistage character in constitutional justice. At the first stage a standard pattern of legal assessment of the facts is created, which has a precedent character and is based on taking into account the reception of an analogy, as well as expressing a certain degree of discretion of judges. At subsequent stages, a specific legal assessment of circumstances is carried out, taking into account / without taking into account the standard option, and depending on the specifics of the considered situation the gaps, uncertainty, inconsistency of legal norms may be established. Conclusions: the author formulates the conclusion that the considered methods of specification of law and legal qualification are interrelated in the process of abstract constitutional control within the concept of meaningmaking, the use of which as a Russian term is preferred in domestic law.
\end{abstract}

Key words: constitutional judicial control, interpretation, specification, legal qualification, meaning-making.

Citation. Gavrilova Yu.A. The Features of the Specification of the Law and Legal Qualification in the Process of Constitutional Judicial Control. Legal Concept, 2019, vol. 18, no. 1, pp. 49-56. (in Russian). DOI: https://doi.org/ 10.15688/lc.jvolsu.2019.1.6

УДК 340.12

Дата поступления статьи: 15.01.2019

ББК 67.0

Дата принятия статьи: 15.02.2019

\section{ОСОБЕННОСТИ КОНКРЕТИЗАЦИИ ПРАВА И ЮРИДИЧЕСКОЙ КВАЛИФИКАЦИИ В ПРОЦЕССЕ КОНСТИТУЦИОННОГО СУДЕБНОГО НОРМОКОНТРОЛЯ}

\author{
Юлия Александровна Гаврилова
}

Волгоградский государственный университет, г. Волгоград, Российская Федерация

Введение: в статье рассмотрена проблема взаимодействия конкретизации права и юридической квалификации в процессе деятельности Конституционного суда Российской Федерации. Данная проблема глу- 
боко не изучена в российском праве. Между тем она имеет существенное теоретическое и практическое значение для развития законодательства и прогнозирования основных тенденций юридической практики. Цель исследования - определить особенности понятий «конкретизация права»» и «юридическая квалификация» в конституционном судопроизводстве. Задачи исследования - осветить основные признаки и роль конкретизации права, охарактеризовать природу и привести примеры юридической квалификации в процедуре абстрактного нормоконтроля. Методы: в статье используются формально-юридический, конкретносоциологический и сравнительно-правовой методы исследования. Результаты: конкретизация права в процессе конституционного судопроизводства имеет многофункциональный целевой характер и по критерию направленности на познание смысла права может быть смыслосохраняющей, смыслоизменяющей и смыслосоздающей. В этом проявляется ее универсальный характер для правовой системы, отличающий ее от конкретизации в правотворчестве и правоприменении. Сущностным признаком конституционно-судебной конкретизации права является также ориентация на конституционализацию правоприменительной практики. Юридическая квалификация в конституционном правосудии имеет многоступенчатый характер. На первом этапе создается типовой шаблон правовой оценки фактов, имеющий прецедентный характер и основанный на учете приема аналогии, а также выражающий известную степень усмотрения судей. На последующих этапах производится конкретная правовая оценка обстоятельств с учетом / без учета типового варианта, и в зависимости от специфики рассматриваемой ситуации могут быть установлены пробелы, неопределенность, несогласованность норм права. Выводы: в заключение автор формулирует вывод о том, что рассмотренные приемы конкретизации права и юридической квалификации в процессе абстрактного конституционного нормоконтроля взаимосвязаны в рамках понятия смыслообразования, использование которого в качестве русского термина является предпочтительным в отечественном праве.

Ключевые слова: конституционный судебный нормоконтроль, интерпретация, конкретизация, юридическая квалификация, смыслообразование.

Цитирование. Гаврилова Ю. А. Особенности конкретизации права и юридической квалификации в процессе конституционного судебного нормоконтроля // Legal Concept = Правовая парадигма. - 2019. T. 18, № 1. - C. 49-56. - DOI: https://doi.org/10.15688/lc.jvolsu.2019.1.6

\section{Введение}

В 1989 г. в рамках советской правовой системы зародился институт конституционного судебного нормоконтроля. Целью его создания являлась защита прав граждан от неконституционных законов и иных нормативных правовых актов, изданных органами высшей публичной власти (Комитет Конституционного надзора СССР). Однако механизм абстрактного конституционного нормоконтроля остается до сих пор не изученным в полном объеме, вопрос о юридической природе актов конституционного правосудия остается самым дискуссионным. Признается, что Конституционный суд Российской Федерации осуществляет официальное нормативное толкование, имеющее для всех обязательный характер. Занимается ли он при этом конкретизацией права, имеет ли такая конкретизация свои отличия от законотворческой и правоприменительной? В чем сущность юридической квалификации в процессе конституционного судопрозводства: связана ли она с непосредственным рассмотрением конкретного дела или же с выполнением функций абстрактного нормоконтроля «на примере конкретного дела»? Данная проблема не раскрыта должным образом в юридической науке и требует пристального анализа. Оговорим, что предметом настоящего исследования не являются особенности региональной конституционной юстиции, которая в едином федеративном правовом пространстве имеет все же свои национально-культурные отличия.

\section{От конституционно-правовой} интерпретации к смыслообразованию
в конституционном судопроизводстве

В плане общей характеристики актов конституционного нормоконтроля часто употребляемой является формулировка «конституционно-правовая интерпретация». При этом в объем данного понятия включаются операции, подтверждающие или опровергающие текстуальный смысл конституционных норм с точки зрения общеправовых принципов и целей регулирования: толкование Конституции Российской Федерации. В объем понятия 
включен и законодательно закрепленный и сформировавшийся в практике смысл отраслевых правовых норм с позиции их конституционной оценки: конкретизация положений Конституции Российской Федерации в федеральных законах и конституционализация правоприменительной практики. Утверждается, что в силу усложненного порядка пересмотра Конституции и затруднительности внесения в нее поправок текст Конституции «преобразуется» и в этот текст вносятся новые элементы понимания смысла по мере длительного развития отношений в обществе. Это дает повод некоторым ученым называть результаты такой деятельности «нормосоздающей», «нормообразующей» и т. п. интерпретацией. Например, дискуссию вызывает мнение Е.В. Тарибо, наделяющего Конституционный суд РФ статусом «позитивного законодателя, формулирующего конституционно-правовое толкование дефектных норм права» [12, с. 20, 21].

Думается, что для описания этого процесса наиболее обобщающим выступает всетаки комплексное понятие смыслообразования, обозначающее набор самых различных правовых средств. Их непреходящая актуальность и ценность заключена в операциях над правовыми смыслами. И главная мысль, неоднократно проводившаяся нами в авторских публикациях, состоит в том, что этот технико-технологический «рецептурный набор» далеко не сводится к одному конституционному истолкованию норм.

Полагаем, что в русском языке термин «толкование» используется в прямом словарном значении - «искать вложенный смысл», то есть не изменяя его и не создавая новый смысл, что именно в практике конституционного правосудия, как раз наоборот, часто и происходит. Уже в этом аспекте понятие смыслообразования отвечает доктринальным требованиям познания отечественного права и задачам развития национальной юридической практики, является более точным и емким для содержательной характеристики всего того, чем во временной динамике занимается орган конституционного судебного нормоконтроля.

Недостаток нормативного регулирования, к которому нередко приходит орган конституционного правосудия в процессе толкования оспариваемых заявителями правовых норм, должен устраняться, но не через «приращение нормативного материала» [6] - это, скорее, цель процесса, - а через «аналогичность» правового мышления и прием мысленной аналогии как правовое средство. П.Д. Блохин в цикле своих публикаций убедительно, на наш взгляд, обосновал ключевую роль этого приема в разработке правовых позиций Конституционного суда Российской Федерации [2, с. 22].

Однако и здесь полемика далеко не заканчивается, поскольку сходство может быть нормативным (аналогичность применяемых норм) и ситуационным (аналогичность установленных фактов). В этой связи согласимся с мнением, что надо четко определиться с тем, что понимается в романо-германском праве под прецедентом [1, с. 14]. Как свидетельствует практика Конституционного суда Российской Федерации, он еще не определился с точным уяснением этого понятия, используя и то, и другое значения. В одном случае говорится о том, что оспариваемая норма является такой же, как и та, в отношении которой уже высказана правовая позиция, и поэтому также подлежит признанию недействительной [8]. В другом случае подчеркивается, что норма права, в отношении которой ранее сформулирована правовая позиция, не может распространяться на гражданина $\mathrm{X}$, поскольку он относится к другой категории лиц, чем та, о которой в первичной правовой позиции говорил орган конституционного судебного нормоконтроля [7].

Кроме того, из процесса конституционного судопроизводства не может быть полностью изъято усмотрение судей. Вопрос о применимости или неприменимости правовых позиций к тем или иным фактам, а также о том, позволяют или не позволяют правовые позиции распространить их действие на новые обстоятельства, отношения или категории лиц, рассматривается всегда конкретно-исторически. По необходимости он включает в процесс принятия решения соответствующий объем судебного усмотрения, в том числе и по отношению к толкованию по объему. До каких пределов понимать или распространить действие смысла нормативного предписания через правовую позицию, чтобы в орбиту этого действия попали требуемые факты [11]? 
Следовательно, толкование во взаимодействии, по меньшей мере с аналогией и усмотрением, приводит к формулированию в конституционном судопроизводстве соответствующего смысла, который практически всегда уточняет, детализирует и развивает содержание законодательного массива. В зависимости от целевой установки такой конкретизации права она может быть смыслосохраняющей (поддерживающей на практике первоначальный законодательный смысл нормы), смыслоизменяющей (корректирующей действующий смысл) и смыслосоздающей (конструирующей новый смысл правовой нормы).

\section{Взаимосвязь конкретизации права и юридической квалификации в конституционном судопроизводстве}

Действующее законодательство обязывает орган конституционного правосудия учитывать официальный буквальный смысл норм законодательства и практики их применения [13]. Однако, рассматривая впервые практику ординарной правовой квалификации по данной категории дел, Конституционный суд Российской Федерации дает типовую «конституционно сообразную» квалификацию единичных фактов, что в сочетании с толкованием конституционно-правового смысла нормы составляет исходную правовую позицию по данному вопросу. Она формулируется методом традиционного «юридического силлогизма» и представляет собой типичный результат конкретизации смысла применяемых норм и принципов права, направленного на обеспечение их конституционного осуществления в общественной жизни [5].

Иным представляется алгоритм действий органа конституционного правосудия при воспроизведении (повторении) в его дальнейшей деятельности «подобных» юридических фактов. Здесь он прибегает ко вторичной юридической квалификации, в рамках которой на основе и помимо конституционной интерпретации оспариваемых норм «по умолчанию» делается акцент на оценку конкретных фактов дела с точки зрения их соответствия ранее высказанной правовой позиции. Осуществляется не традиционный «юридический силлогизм», а особый и более усложненный про- цесс правовой оценки обстоятельств, так как действующая норма права прямо не используется, но подразумевается вместе с правовой позицией, а образцом для сравнения выступают факты, уже получившие оценку в рамках базовой правовой позиции. Вторичная правовая квалификация является зависимой от конституционной модели квалификации этого типа отношений.

Если имеется соответствие фактов этой правовой позиции, первичная правовая позиция обогащается новыми типовыми фактами, подтверждающими ее образцовое регулятивное действие. Она может приобрести со временем универсальный характер не только по сравнению с самой первой нормой, в отношении которой она была дана, но и по отношению ко многим другим нормам, выстраивая относительно самостоятельный блок дополнительных правовых регуляторов. Например, гарантии реализации конституционного права граждан на судебную защиту в разных видах судопроизводств должны быть едиными [9]. Если данное соответствие фактов правовой позиции отсутствует, говорят, что факты не подпадают под смысл правовой нормы с точки зрения имеющейся правовой позиции. При этом они могут служить отправной точкой для изменения или формулирования новой правовой позиции [10].

Такое понимание связи этих феноменов основано на идее, давно критиковавшейся еще со времен советской теории права, о том, что «аналогия - это прием конкретизации». Тем не менее указанная формула конкретизации законодательства в конституционном судопроизводстве через «аналогичное» правовое мышление есть реальность современного конституционного правосудия в России, а этот механизм смыслообразования вряд ли может быть чем-то иным.

Однако наиболее сложный случай имеет место, когда из содержания первичной правовой позиции нельзя усмотреть однозначные правовые последствия или отсутствует нормативное решение для вновь рассматриваемых фактов, либо даже если между несколькими правовыми позициями, сформулированными в разные периоды времени, имеются противоречия. В данных ситуациях имеет место нетипичная конкретизация смысла права, ко- 
торая включает особый юридический состав: 1) конституционное истолкование норм в контексте казуальных фактов; 2) вторичную и производную юридическую квалификацию фактов; 3) логическое следование из исходной правовой позиции дальнейших правовых позиций, имеющих целью устранить конечную пробельность, неопределенность и несогласованность действующих правовых норм в связи с применяемыми в отношении них правовыми позициями.

Результаты любой конкретизации права в процессе осуществления конституционного судебного нормоконтроля могут иметь смыслосохраняющее значение, когда проверяемые нормы права соответствуют Конституции Российской Федерации и найден их единственный конституционно-правовой смысл (по отношению к тенденциям понимания закона в неконституционном смысле они могут иметь одновременно и смыслоизменяющее значение).

Если нормы права, подлежащие проверке, не соответствуют Конституции Российской Федерации и лишаются юридической силы, результатом конкретизации является конструирование нового, как правило дополнительного, смысла правовой нормы, характеризующегося легитимной нормативной новизной: 1) презумпцией доверия к высшему органу конституционного правосудия; 2) презумпцией убедительности аргументации и авторитета его членов; 3) презумпцией отсутствия альтернативных механизмов для принудительного обеспечения исполнения. При надлежащем учете результатов конституционного судебного нормоконтроля в законодательстве элементы выявленной им в практике новизны смысла легализуются, и выработанные конституционно-судебные правовые позиции становятся официальными полноценными юридическими нормами.

Важное значение имеет конструирование в процессе абстрактного конституционного нормоконтроля нового «основного» смысла правовой нормы (или его терминологического эквивалента), что может осуществляться в целях приспособления смысла нормы к изменившимся общественным отношениям, «нового прочтения» буквы и духа нормы. Вопреки распространившемуся сегодня модному понятию «эволютивного» толкования, истоки проникновения которого в российскую правовую доктрину лежат в практике Европейского суда по правам человека, считаем, что актуальная конкретизация смысла нормы в новой исторической обстановке имеет в российском праве форму конструктивного смыслообразования. Отсюда понятие смыслообразования является одним из средств поддержки российской правовой идентичности, не позволяющим любому интерпретатору произвольно претендовать на статус нормотворца «эволютивным», «прогрессивным», «модернизационным» и т. п. путем [3].

\section{Выводы}

1. Несмотря на кажущуюся «избитость» рассмотренных вопросов, настало время признать в российском праве понятие смыслообразования $[4$, с. 17,18$]$. Во-первых, это специфический инструмент защиты национальной правовой системы от чуждого ей внешнего воздействия; во-вторых, оно достаточно полно с позиции словарного состава русского языка позволяет описать многообразную деятельность органов конституционного судебного нормоконтроля и комплексный характер применяемых в этом процессе правовых средств.

2. Особенность конкретизации права в процессе конституционного нормоконтроля состоит в ее всестороннем характере и свойстве быть универсальным источником «кристаллизации» смысла права. С учетом особенностей ситуации она может уточнять технико-редакционные недостатки, раскрывать неопределенное содержание имеющегося смысла, исправлять его дефекты с помощью правовых позиций. Конкретизация права в конституционном судопроизводстве может быть охарактеризована как существенный элемент смыслообразования наряду с конституционноправовой интерпретацией.

3. Особенность юридической квалификации в процессе конституционного нормоконтроля состоит в «наслаивании» друг на друга разных формул правовой квалификации. В этом процессе сочетаются, с одной стороны, поиск и анализ юридических норм на предмет их содержательного сходства, и, с другой стороны, вырабатывается конституционно допусти- 
мая модель квалификации единичных фактов в качестве образца и осуществляется последующая квалификация с точки зрения этой модели каждого конкретного спорного факта. Здесь важная роль принадлежит институту правовой аналогии и усмотрению лиц, осуществляющих конституционное правосудие.

\section{СПИСОК ЛИТЕРАТУРЫ}

1. Антонов, М. В. О некоторых теоретических вопросах прецедентной революции в России / М. В. Антонов // Журнал конституционного правосудия. - 2013. - № 4. - С. 9-15.

2. Блохин, П. Д. Индукция, аналогия, интуиция в конституционно-судебном познании: попытка логико-правового исследования / П. Д. Блохин // Журнал конституционного правосудия. - 2016. № 2. - C. 11-23.

3. Гаврилова, Ю. А. Толковать нельзя интерпретировать $/$ Ю. А. Гаврилова $/ /$ Legal Concept $=$ Правовая парадигма. - 2018. - Т. 17, № 3. - С. 8390. - DOI: https://doi.org/10.15688/lc.jvolsu.2018.3.12.

4. Гаврилова, Ю. А. Юридическое смыслообразование как проблема теории права / Ю. А. Гаврилова // Журнал российского права. - 2017. № 3. - C. 13-20.

5. Гаджиев, Г. А. Методологические проблемы «прецедентной революции» в России / Г. А. Гаджиев // Журнал конституционного правосудия. 2013. - № 4. - C. 4-8.

6. Информация «Конституционно-правовые аспекты совершенствования нормотворческой деятельности (на основе решений Конституционного Суда Российской Федерации 2013-2015 годов)» : (одобрено решением Конституционного Суда РФ от 23.06.2016) // Официальный сайт Конституционного Суда Российской Федерации. - Электрон. текстовые дан. - Режим доступа: http://www.ksrf.ru/. Загл. с экрана.

7. Определение Конституционного Суда Российской Федерации от 25.12.2003 № 448-О «Об отказе в принятии к рассмотрению ходатайства гражданина Гаврюшенко Павла Ивановича об официальном разъяснении Определения Конституционного Суда Российской Федерации от 5 июня 2003 г. № 271-О» - Доступ из справочно-правовой системы «КонсультантПлюс».

8. Определение Конституционного Суда Российской Федерации от 01.12.2005 № 428-О «По жалобе гражданина Шеховцова Егора Владимировича на нарушение его конституционных прав положениями части первой статьи 30 Закона Российской Федерации “О пенсионном обеспечении лиц, проходивших военную службу, службу в органах внутренних дел, Государственной противопожарной службе, органах по контролю за оборотом наркотических средств и психотропных веществ, учреждениях и органах уголовно-исполнительной системы, и их семей”» - Доступ из справочно-правовой системы «КонсультантПлюс».

9. Определение Конституционного Суда Российской Федерации от 24.10.2013 № 1697-О «Об отказе в принятии к рассмотрению жалобы гражданина Балошко Василия Юрьевича на нарушение его конституционных прав статьями 27.7 и 27.10 Кодекса Российской Федерации об административных правонарушениях»- Доступ из справочно-правовой системы «КонсультантПлюс».

10. Определение Конституционного Суда Российской Федерации от 27.06.2017 № 1239-О «Об отказе в принятии к рассмотрению жалобы гражданина Хмызникова Сергея Константиновича на нарушение его конституционных прав частями 5 и 6 статьи 43 Федерального закона “О полиции””. - Доступ из справочно-правовой системы «КонсультантПлюс».

11. Постановление Конституционного Суда Российской Федерации от 17.04.2018 № 15-П «По делу о проверке конституционности положений подпункта "а" пункта 2 статьи 24 Федерального закона "О воинской обязанности и военной службе” в связи с жалобой гражданина П.А. Спиридонова и запросом Бугульминского городского суда Республики Татарстан» - Доступ из справочно-правовой системы «КонсультантПлюс».

12. Тарибо, Е. В. Поиск оптимального решения при осуществлении конституционного нормоконтроля / Е. В. Тарибо // Журнал конституционного правосудия. - 2018. - № 1. - С. 17-21.

13. Федеральный конституционный закон «О Конституционном Суде Российской Федерации» от 21.07.1994 № 1-ФК3 // Российская газета. 1994. - 23 июля (№ 138-139).

\section{REFERENCES}

1. Antonov M.V. O nekotorykh teoreticheskikh voprosakh pretsedentnoy revolyutsii v Rossii [On Some Theoretical Issues of the Precedent Revolution in Russia]. Zhurnal konstitutsionnogo pravosudiya, 2013, no. 4, pp. 9-15.

2. Blokhin P.D. Induktsiya, analogiya, intuitsiya v konstitutsionno-sudebnom poznanii: popytka logikopravovogo issledovaniya [Induction, Analogy, Intuition in Constitutional and Judicial Knowledge: an Attempt at Logical-Legal Research]. Zhurnal konstitutsionnogo pravosudiya, 2016, no. 2, pp. 11-23.

3. Gavrilova Yu.A. Tolkovat nelzya interpretirovat [To Construe Cannot be to Interpret]. Legal Concept $=$ 
Pravovaya paradigma, 2018, vol. 17, no. 3, pp. 83-90. DOI: https://doi.org/10.15688/lc.jvolsu.2018.3.12.

4. Gavrilova Yu.A. Yuridicheskoe smysloobrazovanie kak problema teorii prava [Legal Sense Formation as a Problem of the Theory of Law]. Zhurnal rossiyskogo prava, 2017, no. 3, pp. 13-20.

5. Gadzhiev G.A. Metodologicheskie problemy «pretsedentnoy revolyutsii» v Rossii [Methodological Problems of the "Precedent Revolution" in Russia].Zhurnal konstitutsionnogo pravosudiya, 2013, no. 4, pp. 4-8.

6. Informatsiya «Konstitutsionno-pravovye aspekty sovershenstvovaniya normotvorcheskoy deyatelnosti (na osnove resheniy Konstitutsionnogo Suda Rossiyskoy Federatsii 2013-2015 godov)» (odobreno resheniem Konstitutsionnogo Suda RF ot 23.06.2016) [Information "Constitutional and Legal Aspects of the Improvement of Rule-Making Activities (Based on Decisions of the Constitutional Court of the Russian Federation 2013-2015)" (Approved by the Decision of the Constitutional Court of the Russian Federation Dated 06.23.2016)]. Oficialnyy sayt Konstitutsionnogo Suda Rossiyskoy Federatsii [The Official Website of the Constitutional Court of the Russian Federation]. URL: http://www.ksrf.ru/.

7. Opredelenie Konstitutsionnogo Suda Rossiyskoy Federatsii ot 25.12.2003№ 448-O «Ob otkaze $v$ prinyatii $k$ rassmotreniyu hodataystva grazhdanina Gavryushenko Pavla Ivanovicha ob oficialnom razyasnenii Opredeleniya Konstitutsionnogo Suda Rossiyskoy Federatsii ot 5 iyunya 2003 g. № 271-O» [Determination of the Constitutional Court of the Russian Federation of December 25, 2003 No. 448-O "On Refusal to Accept the Petition of Citizen Gavryushenko Pavel Ivanovich for Official Clarification of the Definition of the Constitutional Court of the Russian Federation of June 5, 2003 No. 271-O"]. Access from Reference Legal System 'Consultant Plus'.

8. Opredelenie Konstitutsionnogo Suda Rossiyskoy Federatsii ot 01.12.2005 № 428-O "Po zhalobe grazhdanina Shekhovtsova Egora Vladimirovicha na narushenie ego konstitutsionnykh prav polozheniyami chasti pervoy stati 30 Zakona Rossiyskoy Federatsii «O pensionnom obespechenii lits, prohodivshikh voennuyu sluzhbu, sluzhbu v organakh vnutrennikh del, Gosudarstvennoy protivopozharnoy sluzhbe, organakh po kontrolyu za oborotom narkoticheskikh sredstv i psihotropnykh veshchestv, uchrezhdeniyakh i organakh ugolovnoispolnitelnoy sistemy, $i$ ikh semey» [The Definition of the Constitutional Court of the Russian Federation of 01.12.2005 No. 428-O "On the Complaint of Citizen Shekhovtsov Egor Vladimirovich about the Violation of his Constitutional Rights by the Provisions of the First Part of Article 30 of the Law of the Russian Federation" On the Pension Security of Persons who Served in the Military the Fire Service, Drug and Psychotropic
Substances Control Authorities, Institutions and Bodies of the Penitentiary System, and their Families "]. Access from Reference Legal System 'Consultant Plus'.

9. Opredelenie Konstitutsionnogo Suda Rossiyskoy Federatsii ot 24.10.2013 № 1697-O "Ob otkaze v prinyatii k rassmotreniyu zhaloby grazhdanina Baloshko Vasiliya Yuryevicha na narushenie ego konstitutsionnykh prav statyami $27.7 i$ 27.10 Kodeksa Rossiyskoy Federatsii ob administrativnykh pravonarusheniyakh» [Determination of the Constitutional Court of the Russian Federation of 24.10.2013 No. 1697-O "On the Refusal to Accept for Consideration of the Complaint of a Citizen Baloshko Vasily Yuryevich about Violation of his Constitutional Rights by Articles 27.7 and 27.10 of the Administrative Offenses Code of the Russian Federation"]. Access from Reference Legal System 'Consultant Plus'.

10. Opredelenie Konstitutsionnogo Suda Rossiyskoy Federatsii ot 27.06.2017 № 1239-O "Ob otkaze $v$ prinyatii $k$ rassmotreniyu zhaloby grazhdanina Hmyznikova Sergeya Konstantinovicha na narushenie ego konstitutsionnykh prav chastyami 5 i 6 stati 43 Federalnogo zakona "O politsii"” [Determination of the Constitutional Court of the Russian Federation of 27.06.2017 No. 1239-O "On the Refusal to Accept for Consideration of the Complaint of the Citizen Khmyznikov Sergey Konstantinovich about Violation of his Constitutional Rights by Parts 5 and 6 of Article 43 of the Federal Law "On the Police"]. Access from Reference Legal System 'Consultant Plus'.

11. Postanovlenie Konstitutsionnogo Suda Rossiyskoy Federatsii ot 17.04.2018 № 15-P «Po delu o proverke konstitutsionnosti polozheniy podpunkta " $a$ " punkta 2 stati 24 Federalnogo zakona "O voinskoy obyazannosti i voennoy sluzhbe" $v$ svyazi s zhaloboy grazhdanina P.A. Spiridonova $i$ zaprosom Bugulminskogo gorodskogo suda Respubliki Tatarstan» [Resolution of the Constitutional Court of the Russian Federation of April 17, 2017 No. 15-P "On the Case of Verifying the Constitutionality of the Provisions of Subitem" a "of paragraph 2 of Article 24 of the Federal Law" On Conscription and Military Service "in connection with the complaint of citizen P. Spiridonov and the request of the Bugulma City Court of the Republic of Tatarstan"]. Access from Reference Legal System 'Consultant Plus'.

12. Taribo E.V. Poisk optimalnogo resheniya pri osushchestvlenii konstitutsionnogo normokontrolya [The Search for the Optimal Solution in the Implementation of Constitutional Monitoring]. Zhurnal konstitutsionnogo pravosudiya, 2018, no. 1, pp. 17-21.

13. Federalnyy konstitutsionnyy zakon «O Konstitutsionnom Sude Rossiyskoy Federatsii» ot 21.07.1994 № 1-FKZ [Federal Constitutional Law "On the Constitutional Court of the Russian Federation" of 21.07.1994 No. 1-FKZ]. Rossiyskaya gazeta, 1994, 23 July, no. 138-139. 


\section{Information about the Author}

Yuliya A. Gavrilova, Candidate of Sciences (Jurisprudence), Associate Professor, Department of Theory and History of Law and State, Volgograd State University, Prosp. Universitetsky, 100, 400062 Volgograd, Russian Federation, gavrilova_ua@volsu.ru, https://orcid.org/0000-0002-8055-4710

\section{Информация об авторе}

Юлия Александровна Гаврилова, кандидат юридических наук, доцент кафедры теории и истории права и государства, Волгоградский государственный университет, просп. Университетский, 100, 400062 г. Волгоград, Российская Федерация, gavrilova_ua@volsu.ru, https://orcid.org/0000$0002-8055-4710$ 